\title{
Comparison between Single- and Double-Injection Technique for Ultrasound-Guided Supraclavicular Block: A Randomized Controlled Study
}

\author{
Suresh Kumar Vallapureddy ${ }^{a} \quad$ Gajanan Fultambkar $^{\mathrm{a}} \quad$ V. Rajeswar Rao ${ }^{\mathrm{a}}$ \\ Vinay Kukreja $^{a}$ Rammohan Gurram ${ }^{a}$ Abhijit Nair \\ ${ }^{a}$ Department of Anesthesiology, Yashoda Hospital, Secunderabad, India; ${ }^{b}$ Department of Anesthesiology, Ibra Hospital, \\ Ibra, Sultanate of Oman
}

\section{Keywords}

Acute pain - Brachial plexus - Regional anesthesia ·

Supraclavicular block - Ultrasonography

\begin{abstract}
Background: The supraclavicular approach to brachial plexus block is a commonly employed regional anesthesia technique for providing surgical anesthesia and postoperative analgesia for patients undergoing upper limb fractures. With ultrasound (US) guidance, the success rate of the block is increased, and complications like pneumothorax and vascular puncture are minimized. The block can be performed using single injection at the corner pocket or double injection, that is, half of the drug at the corner pocket and the remaining half at the cluster of brachial plexus divisions. Methods: After institutional ethics committee approval, we randomized 40 patients scheduled with fractures for elective upper extremity surgery under US-guided supraclavicular brachial plexus block. Twenty patients received $30 \mathrm{~mL}$ of local anesthetic at the corner pocket (group SI), and 20 patients received $30 \mathrm{~mL}$ of local anesthetic using the dual-injection technique in divided doses (group DI). Demographic data, time to block performance, time to sensory and motor block, total anesthesia-related time (TART), block success, and failure were compared between both groups. Results: The demographic
\end{abstract}

data were comparable between both groups. The DI group had a significantly faster onset than the SI group ( $p=0.0172$ ). There was a statistically significant lesser performance time in group SI than in group DI $(p<0.034)$. The sensory and motor block achieved was comparable between both groups. Conclusion: The success rates in both the SI and DI techniques are comparable. The DI technique results in a faster onset and hence a shorter TART; however, it may not be clinically relevant.

(C) 2021 The Author(s)

Published by S. Karger AG, Basel

\section{Introduction}

The supraclavicular approach to brachial plexus block (SCBPB) or the supraclavicular block (SCB) anesthetizes the brachial plexus providing a complete and reliable blockade for upper extremity surgery [1]. The most important requirement for successful regional anesthetic block is exact needle position and proper delivery of the local anesthetic (LA). After the advent of ultrasound (US) in regional anesthesia, it was possible to verify the accurate location of the needle tip in relation to the nerves and distribution of LA. In addition, it helped to avoid complications such as intraneuronal and intravascular injection. Real-time USG improves the block quality, shortens its karger@karger.com www.karger.com/dmj

Karger $\stackrel{\text { ' }}{5}$

GOPEN ACCESS
(C) 2021 The Author(s)

Published by S. Karger AG, Basel

This is an Open Access article licensed under the Creative Commons Attribution-NonCommercial-4.0 International License (CC BY-NC) (http://www.karger.com/Services/OpenAccessLicense), applicable to the online version of the article only. Usage and distribution for commercial purposes requires written permission.
Correspondence to:

Abhijit Nair, abhijitnair95@outlook.com 
latency, and reduces the minimum volume required to obtain a successful nerve block [2].

Techniques for US-guided SCB consist of injecting the entire volume of LA at the intersection of the first rib and the subclavian artery (the "corner pocket" technique) or entire volume of LA at the cluster. This is also known as the single-injection (SI) technique. In a double-injection (DI) technique, half the volume is deposited at the corner pocket and the other half is injected inside the neural cluster [3-5]. The US-guided corner pocket technique (SI) has been reported to have the highest success rate, but the disadvantage of this technique is that it may miss the upper part of the plexus, leading to an incomplete blockade [6]. Several studies have been done comparing different approaches for brachial plexus block and showed that multiple injection techniques tend to be more successful, resulting in a faster onset of anesthesia and higher success rates with least complications. However, these studies did not demonstrate regarding the onset of block or the nerves blocked. Despite good success rates reported with these US-SCB using single or multiple injections, no consensus exists on the best technique to use.

The aim of this study was to compare the success rate of US-guided SI and DI techniques for upper limb surgery. Secondary outcomes were to compare total procedure time and complications if any.

\section{Materials and Methods}

After obtaining institutional ethics committee, 40 American Society of Anesthesiologists' physical status (ASA-PS) I/II patients posted for elective upper limb surgeries were enrolled from December 2018 to April 2019 in this prospective, randomized, controlled study. Patients between age 18 and 70 years and BMI between 20 and $35 \mathrm{~kg} / \mathrm{m}^{2}$ were included. Patients with ASA-PS III or more, patients with cardiac diseases, hepatic or renal impairment, coagulopathy, emergency upper limb surgeries, and patients refusing enrollment were excluded. Random assignment was carried out by allocating patients into 2 groups. Simple randomization was adopted with a computer-generated random number allocation sequence. Group allocation was concealed in sealed, opaque envelopes. Patients were randomized into 2 groups: group SI, in which patients received single injection at the corner pocket, and group DI, in which patients received 2 injections, at the corner pocket and at the cluster. A thorough preoperative evaluation was done, and routine investigations like complete blood picture, blood group, and serum creatinine were ordered and reviewed. After confirming 6-h nil oral status, patients were shifted to the operation room. Patients were monitored by ECG, pulse oximetry, and NIBP. An appropriately sized intravenous (IV) access was secured on the contralateral upper extremity. IV midazolam $0.03 \mathrm{mg} / \mathrm{kg}$ was given before the surgery.

Single versus Double-Injection

Supraclavicular Brachial Plexus Block
All blocks were performed by using the US machine (GE Logitech Venue 40) with an 8- to $12-\mathrm{MHz}$ linear type probe. All patients were placed in the supine position with their heads turned contralateral. Under due asepsis, the US probe was positioned in the supraclavicular fossa and scanned to locate the subclavian artery and brachial plexus cluster. A skin wheal was raised with $2 \mathrm{~mL}$ of lidocaine $2 \%$. Once the artery, rib, pleura, and plexus were simultaneously in view, the needle was guided, using an in-plane technique, toward the "corner pocket" between the first rib inferiorly, the subclavian artery medially, and the nerves superiorly.

Confirming that the location of the needle tip was not in hypoechoic nodules (in nerves), $0.5 \mathrm{~mL}$ of LA was injected as a test dose to avoid intraneural injection. If the patients did not complain of paresthesia/pain or there was no excessive resistance to injection, a total volume of $30 \mathrm{~mL}$ of LA was injected. This volume was derived from a study conducted by Sayed et al. [7].

In group SI, the entire $30 \mathrm{~mL}$ was injected in the corner pocket. In group DI, the volume was divided, that is, $15 \mathrm{~mL}$ was deposited in the corner pocket, and during withdrawal of the needle, the remaining $15 \mathrm{~mL}$ was injected superior and lateral to the subclavian artery in the center of the brachial plexus. Data were collected by an assessor blinded to the patient's volume assignments. Imaging time was defined as the time interval between contact of the US probe with the patient and the acquisition of a satisfactory picture. The needling time was defined as the temporal interval between the start of the skin wheal and the end of LA injection through the block needle. Performance time was defined as the sum of imaging and needling times. Total anesthesia-related time was the sum of imaging time, needling time, and performance time which was noted. The extent of sensory and motor blockade was tested by a blinded observer every $5 \mathrm{~min}$ until $30 \mathrm{~min}$.

Sensory blockade of the musculocutaneous, median, radial, and ulnar nerves was graded according to a 3-point scale using a cold test (grade $0=$ no block; $1=$ analgesia, i.e., patient can feel touch, not cold; 2 = anesthesia, i.e., patient cannot feel touch). Sensory blockade of the musculocutaneous, median, radial, and ulnar nerves was assessed on the lateral aspect of the forearm, the volar aspect of the thumb, the lateral aspect of the dorsum of the hand, and the volar aspect of the fifth finger, respectively.

Motor blockade was graded on a 3-point scale (grade $0=$ no block, 1 = paresis, and 2 = paralysis). Motor blockade of the musculocutaneous, radial, median, and ulnar nerves was evaluated by elbow flexion, thumb abduction, thumb opposition, and thumb adduction, respectively. Overall, the maximal composite score was 16 points. The block was considered successful when a composite score of 14 was achieved. Composite score $<14$ was considered as failure of blockade and is converted to general anesthesia. Onset time was defined as the time required to obtain 14 points. Patients developing adverse events like Horner's syndrome, voice change, and chest discomfort or dyspnea were noted. The patients with failed blockades and those with severe complications such as arrhythmias, hypotension, and desaturation received general anesthesia. If in case surgery was unduly prolonged and the effect of the block wore off, rescue analgesia was given in the form of IV fentanyl $1 \mu \mathrm{g} / \mathrm{kg}$ and infusion of propofol $50-100 \mu \mathrm{g} / \mathrm{kg} / \mathrm{min}$. The patient was blinded to the type of intervention, but the investigator was not blinded and was aware about the type of block.

The collected data were tabulated and analyzed by using Statistical Package for Social Sciences (SPSS) Windows version 24.0

Dubai Med J 2021;4:198-203 


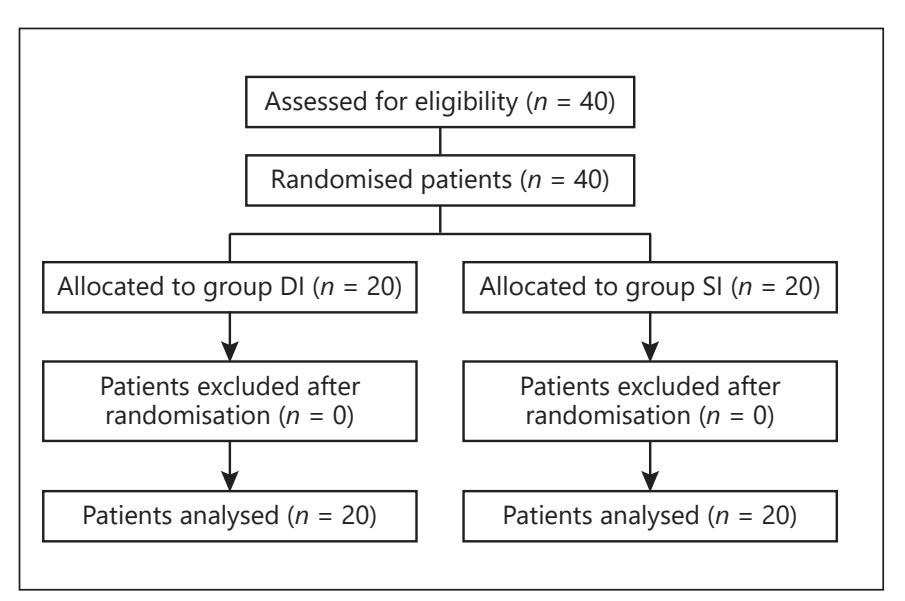

Fig. 1. CONSORT diagram.

software. The Kolmogorov-Smirnov test was used to determine whether the variables were normally distributed. Unpaired $t$ test was used for analysis for continuous data which was normally distributed and the Mann-Whitney test for skewed distribution. Categorical data were in the form of absolute numbers and/or percentage. Fisher exact test was used to analyze categorical data. A $p$ value $<0.05$ was considered statistically significant.

\section{Results}

The study was carried out on a total of 40 patients operated under US-guided SCBPB. The CONSORT diagram is depicted in Figure 1. Demographic data, success rate, imaging time, needling time, performance time, onset time, total anesthesia-related time, adverse perioperative events, and complications were compared between group SI and group DI. Demographic data (age, weight, height, BMI, and ASA-PS) were comparable between both groups $(p>0.05)$ (Table 1$)$.

Ninety-five percent of patients in DI and $90 \%$ of patients in SI achieved a composite score of $>14$ which was not statistically significant $(p=0.382)$ (Table 2$)$. In group SI, none of the patients had an imaging time of $>5 \mathrm{~min}$; in $40 \%$ patients, the time was $<1 \mathrm{~min}$; and for the other patients, the time was between 1 and $5 \mathrm{~min}$. In group DI, $10 \%$ of patients had an imaging time of $>5$ $\mathrm{min}$; in $20 \%$ patients, $<1 \mathrm{~min}$; and the remaining between 1 and $5 \mathrm{~min}$. The needling time was $<1 \mathrm{~min}$ in $35 \%$ of patients in SI and $10 \%$ in DI. The performance time was $<1 \mathrm{~min}$ in $35 \%$ of patients in SI and $15 \%$ in DI. There was a statistically significant lesser performance time in group SI than in group DI (median 1 [1-2] compared to $1[2-3], p$ value of 0.034$)$. Imaging and nee-
Table 1. Comparison of demographic data between 2 groups

\begin{tabular}{lccl}
\hline Variable & Group DI & Group SI & $p$ value \\
\hline Age & $49.37 \pm 16.79$ & $45.35 \pm 16.25$ & 0.186 \\
Gender & $12(60)$ & $12(60)$ & 1 \\
$\quad$ Male & $8(40)$ & $8(40)$ & \\
$\quad$ Female & 9 & 10 & 1 \\
ASA-PS & 11 & 10 & \\
$\quad$ I & $67.90 \pm 10.23$ & $68.43 \pm 8.57$ & 0.757 \\
$\quad$ II & $166.15 \pm 6.72$ & $164.20 \pm 13.53$ & 0.319 \\
Weight & $24.79 \pm 3.31$ & $24.85 \pm 3.30$ & 0.920 \\
Height & & & \\
BMI & & & \\
\hline
\end{tabular}

Table 2. Comparison of the composite point between both groups

\begin{tabular}{lllll}
\hline $\begin{array}{l}\text { Composite } \\
\text { point }\end{array}$ & $\begin{array}{l}\text { Group DI, } \\
n(\%)\end{array}$ & $\begin{array}{l}\text { Group SI, } \\
n(\%)\end{array}$ & $\begin{array}{l}\text { Total, } \\
n(\%)\end{array}$ & $\begin{array}{l}p \\
\text { value }\end{array}$ \\
\hline$<14$ & $1(5)$ & $2(10)$ & $3(7.5)$ & \\
$\geq 14$ & $19(95)$ & $18(90)$ & $37(92.5)$ & 0.382 \\
Total & $20(100)$ & $20(100)$ & $40(100)$ & \\
\hline
\end{tabular}

$p=0.382$; not significant; Fisher exact test.

Table 3. Comparison of total anesthesia-related time between both groups

\begin{tabular}{llll}
\hline & Group DI & Group SI & $p$ value \\
\hline Imaging time & $2(0)$ & $2(1-2)$ & 0.164 \\
Needling time & $2(2)$ & $2(1-2)$ & 0.18 \\
Performance time & $1(2-3)$ & $1(1-2)$ & 0.034 \\
\hline
\end{tabular}

Presented as median (interquartile range), $p<0.001$; significant; Mann-Whitney test.

Table 4. Onset time distribution in 2 groups

\begin{tabular}{lccc}
\hline Onset time & Group DI, $n(\%)$ & Group SI, $n(\%)$ & $p$ value \\
\hline$<15$ & $3(15)$ & 0 & \\
$15-25$ & $17(65)$ & $15(75)$ & 0.0172 \\
$>25$ & $0(0)$ & $5(25)$ & \\
\hline
\end{tabular}

$p<0.001$, significant; Fisher exact test. 
Table 5. Comparison of sensory blockade between both groups

\begin{tabular}{lccc}
\hline Sensory blockade & $\begin{array}{c}\text { Group DI } \\
(n=20)\end{array}$ & $\begin{array}{c}\text { Group SI } \\
(n=20)\end{array}$ & $p$ value \\
\hline $\begin{array}{l}\text { Musculocutaneous, } n(\%) \\
\quad\end{array}$ & $0(0)$ & $0(0)$ & \\
0 & $1(5)$ & $2(10)$ & 0.584 \\
1 & $19(95)$ & $18(90)$ & \\
2 & & & \\
Median, $n(\%)$ & $0(0)$ & $0(0)$ & \\
0 & $0(0)$ & $1(5)$ & 0.311 \\
1 & $20(100)$ & $19(95)$ & \\
2 & & & \\
Radial, $n(\%)$ & $0(0)$ & $0(0)$ & \\
0 & $1(5)$ & $0(0)$ & 0.311 \\
1 & $19(95)$ & $20(100)$ & \\
2 & & & \\
Ulnar, $n(\%)$ & $2(10)$ & $3(15)$ & \\
0 & $1(5)$ & $0(0)$ & 0.548 \\
1 & $17(85)$ & $17(85)$ & \\
2 & & & \\
\hline
\end{tabular}

dling times were comparable (Table 3 ). The onset time was $>25 \mathrm{~min}$ in $25 \%$ of patients in SI and none in DI, whereas $15 \%$ of patients had an onset $<15 \mathrm{~min}$ in DI and none in SI. The DI group had a significantly faster onset than the SI group $(p=0.0172)$ (Table 4$)$. The sensory and motor blockades of musculocutaneous, median, radial, and ulnar nerve distribution were comparable between both groups (Tables 5,6). The patients who did not achieve the composite score of 14 were labeled as block failure and converted to GA. One patient in the DI group and 2 patients in the SI group received GA due to block failure. No adverse perioperative events or complications were noted in either groups.

\section{Discussion}

In our study, we found that both the techniques provide similar success rates of surgical anesthesia. The onset time is faster in the DI group when compared to SI. The performance time was longer in group DI in comparison with group SI probably because group DI required more needle maneuvering. However, the additional needle maneuvering did not lead to an increase in the incidence of vascular puncture, paresthesia, or postoperative neurologic deficits.

SCBPB is performed to provide surgical anesthesia and perioperative analgesia for surgeries of the forearm. At the supraclavicular area, the trunks of the brachial

Single versus Double-Injection

Supraclavicular Brachial Plexus Block
Table 6. Comparison of motor blockade between both groups

\begin{tabular}{|c|c|c|c|}
\hline Motor blockade & $\begin{array}{l}\text { Group DI } \\
(n=20)\end{array}$ & $\begin{array}{l}\text { Group SI } \\
(n=20)\end{array}$ & $\begin{array}{l}p \\
\text { value }\end{array}$ \\
\hline \multicolumn{4}{|c|}{ Musculocutaneous, $n(\%)$} \\
\hline 0 & $0(0)$ & $0(0)$ & \multirow{3}{*}{0.584} \\
\hline 1 & $1(5)$ & $2(10)$ & \\
\hline 2 & $19(95)$ & $18(90)$ & \\
\hline \multicolumn{4}{|l|}{ Median, $n(\%)$} \\
\hline 0 & $0(0)$ & $0(0)$ & \multirow{3}{*}{0.311} \\
\hline 1 & $0(0)$ & $1(5)$ & \\
\hline 2 & $20(100)$ & $19(95)$ & \\
\hline \multicolumn{4}{|l|}{ Radial, $n(\%)$} \\
\hline 0 & $0(0)$ & $0(0)$ & \multirow{3}{*}{0.311} \\
\hline 1 & $1(5)$ & $0(0)$ & \\
\hline 2 & $19(95)$ & $20(100)$ & \\
\hline \multicolumn{4}{|l|}{ Ulnar, $n(\%)$} \\
\hline 0 & $2(10)$ & $3(15)$ & \multirow{3}{*}{0.548} \\
\hline 1 & $1(5)$ & $0(0)$ & \\
\hline 2 & $17(85)$ & $17(85)$ & \\
\hline
\end{tabular}

plexus are available for the anesthesiologist to perform a block. With US, the trunks are visible as a bunch of grapes situated superolateral to the pulsations of the subclavian artery. In the 1-point injection technique, the LA is deposited near the plexus, but this leads to ulnar sparing thus compromising the success of the block. This happens because the inferior trunk is situated medially, and a needle entry intended to enter in that fashion carries a high risk of pneumothorax.

Performing an "8-ball corner pocket technique" for SCBPB involves the deposition of LA in the pocket formed by the subclavian artery laterally and the first rib inferiorly. This has shown to provide faster onset and also had a higher success as the ulnar nerve is blocked in $85 \%$ of the cases [8]. Tran et al. [9] randomized 92 patients into 2 groups (46 patients in each group) to receive a singleinjection US-guided SCBPB at the clusters or a double injection, at the corner pocket and at the cluster. The LA used was $35 \mathrm{~mL} \mathrm{1.5 \%} \mathrm{lidocaine} \mathrm{with} 5 \mu \mathrm{g} / \mathrm{mL}$ epinephrine. For single injection, entire $35 \mathrm{~mL}$ was injected at the cluster, and in the double injection, $20 \mathrm{~mL}$ was deposited at the corner pocket and $15 \mathrm{~mL}$ at the cluster. On analysis, the authors concluded that onset of sensory and motor block was faster with double injection than the single injection at the cluster which was similar to our findings. Success rate, pain scores, and complications were comparable between both groups.

Sayed and Sobhy [7] randomized 100 patients into 2 groups of 50 each to receive US-SCBPB with either a 
single injection at the cluster or a dual injection, at corner pocket and cluster, using $30 \mathrm{~mL}$ of $0.5 \%$ bupivacaine. In the dual-injection group, the volume was divided into $15 \mathrm{~mL}$ at each location. The authors concluded that single-injection US-SCB was faster in performance with less incidence of paresthesia than the dual-injection technique. Time taken for sensory and motor block was comparable. These results were similar to our findings.

Chaudhary et al. [10] randomized 60 ASA-PS I/II patients into 2 groups of 30 each who received SI versus DI US-guided SCBPB for forearm surgeries. They injected $20 \mathrm{~mL}$ of $0.5 \%$ bupivacaine volume in each group (in SI: $20 \mathrm{~mL}$ in cluster; in DI: $10 \mathrm{~mL}$ in corner pocket and $10 \mathrm{~mL}$ in cluster). On analysis, the authors concluded that the DI group had greater success rate compared to SI (96.7 vs. $83.3 \% ; p<0.0001)$ and procedural time was more in group DI than SI $(14.6 \pm 2.7$ vs. $10.1 \pm 1.7 \mathrm{~min} ; p<0.0001)$. The onset of sensory and motor block was faster in group DI, and duration of sensory and motor block was longer in the DI group than group SI. Contrary to these results, in our study, the success rate was comparable between both groups.

In a randomized study involving 102 patients divided into 2 groups of 51 each of patients for forearm surgeries, Roy et al. [11] performed US-guided SCBPB using $30 \mathrm{~mL}$ of $1.5 \%$ mepivacaine. In group D, patients received injection at the corner pocket and cluster $(15 \mathrm{~mL}$ each $)$, and in group S, $30 \mathrm{~mL}$ was injected at the cluster. The authors concluded that the rate of onset of sensory, motor, and surgical block was similar in both techniques. Techasuk et al. [12] randomized 90 patients into 2 groups to receive either a single injection at cluster or a dual injection, at the cluster and at the corner pocket. The LA used in this study was $1.5 \%$ lidocaine with $5 \mu \mathrm{g} / \mathrm{mL}$ epinephrine, and the total volume injected was $16 \mathrm{~mL}$. On analysis, the authors found that there was quicker onset and therefore a lesser total anesthesia time in the double-injection group when compared to single injection at the cluster (10.1 \pm 6.4 vs. $18.5 \pm 8.3 \mathrm{~min} ; p<0.0001)$. The success rate was comparable in both groups.

Injection of the drug directly around the plexus could lead to the formation of smaller satellite clusters, resulting in the increase in the surface area of exposure of the nerves to the LA [13]. This could explain the faster onset of the blockade in the DI group observed in the study. However, safety regarding the direct placement of the needle in the brachial plexus cluster is not established. In an observational study conducted by Bigeleisen et al. [14], the authors mentioned that the positioning of the needle tip in the cluster was equivalent to intraneural placement. In an editorial by Franco [15], it was mentioned that intracluster injection of LA did not amount to true intraneuronal injection. Irrespective of the fact whether LA injected into the neural cluster amounts to true intraneuronal injection, recent evidence supports the safety of the DI technique $[16,17]$. There was no incidence of paresthesia or any other adverse neurological outcome in our study, thus confirming the safety of the DI technique.

There were several limitations to this study. The study was conducted in a small number of subjects, and therefore there is no evidence that success rate is different based on the small number of data analyzed. Moreover, the probability of type II error was high. Larger number of subjects can be added in further studies. We did not restrict to a single type of surgical procedure, so that there could be a chance to eliminate any confounding factors arising from the surgical stimulus or location of the surgery. The anesthesiologist was not blinded as it was obvious which technique was been employed. This was another limitation. Moreover, time to rescue analgesic postoperatively was not compared, and patients were not followed up after surgery for knowing time to rescue analgesia.

In conclusion, based on the analysis of results, there is no evidence that the success rate is different with either approaches with the present sample size. The DI technique appears to have a faster onset and hence a shorter performance time which may not be clinically relevant. The double injection is a safe and reliable technique of US-guided SCB for upper limb surgeries.

\section{Statement of Ethics}

The study was approved by the Institutional Ethics Committee, Yashoda Academy of Medical Education and Research (IECYAMER), R. No. ECR/49/Inst/AP/2013/RR-16, DNBT-91/2018, dated December 17, 2018. A written, informed consent was obtained from all patients to participate in the study.

\section{Conflict of Interest Statement}

The authors have no conflicts of interest to declare.

\section{Funding Sources}

None of the authors have obtained external funding anywhere. 


\section{Author Contributions}

S.K.V. was responsible for definition of intellectual content, manuscript preparation, analysis of data, and performing the procedure. G.F. performed review of the literature, edited the manuscript, and defined intellectual content. V.R.R. defined intellectual content and designed the study. V.K. helped in manuscript preparation and data collection. R.G. helped in manuscript editing, def- inition of intellectual content, and designing the study. A.N. performed review of the literature, edited and reviewed the manuscript, and analyzed the data.

\section{Data Availability Statement}

Data are available on request due to privacy/ethical restrictions.

\section{References}

1 John RS, Mckean G, Sarkar RA. Upper limb block anesthesi. In: StatPearls [Internet]. Treasure Island, FL: StatPearls Publishing; 2021. [Updated 2021 Jan 19]. Available from: https://www.ncbi.nlm.nih.gov/books/ NBK531460/ Accessed 2021 Feb 27.

2 Liu SS. Evidence basis for ultrasound-guided block characteristics onset, quality, and duration. Reg Anesth Pain Med. 2016 Mar-Apr; 41(2):205-20.

3 D'Souza RS, Johnson RL. Supraclavicular block. In: StatPearls [Internet]. Treasure Island, FL: StatPearls Publishing; 2021. [Updated 2020 Aug 15]. Available from: https:// www.ncbi.nlm.nih.gov/books/NBK519056/ Accessed 2021 Feb 27.

4 Soares LG, Brull R, Lai J, Chan VW. Eight ball, corner pocket: the optimal needle position for ultrasound-guided supraclavicular block. Reg Anesth Pain Med. 2007 Jan-Feb;32(1):94-5.

5 Hanumanthaiah D, Vaidiyanathan S, Garstka M, Szucs S, Iohom G. Ultrasound guided supraclavicular block. Med Ultrason. 2013; 15(3):224-9.

6 Fredrickson MJ, Patel A, Young S, Chinchanwala S. Speed of onset of 'corner pocket supraclavicular' and infraclavicular ultrasound guided brachial plexus block: a randomised observer-blinded comparison. Anaesthesia. 2009;64(7):738-44.
7 Sayed AA, Sobhy A. Levobupivacaine in single-injection versus dual-injection ultrasound-guided supraclavicular brachial plexus block. Ain-Shams J Anaesthesiol. 2014;7(2): 182-6.

8 Brull R, Chan VW. The corner pocket revisited. Reg Anesth Pain Med. 2011 May-Jun; 36(3):308.

9 Tran DQ, Muñoz L, Zaouter C, Russo G, Finlayson RJ. A prospective, randomized comparison between single- and double-injection, ultrasound-guided supraclavicular brachial plexus block. Reg Anesth Pain Med. 2009 Sep-Oct;34(5):420-4.

10 Choudhary N, Kumar A, Kohli A, Wadhawan S, Siddiqui TH, Bhadoria P, et al. Single-point versus double-point injection technique of ultrasound-guided supraclavicular block: a randomized controlled study. J Anaesthesiol Clin Pharmacol. 2019 Jul-Sep;35(3):373-8.

11 Roy M, Nadeau MJ, Côté D, Levesque S, Dion $\mathrm{N}$, Nicole PC, et al. Comparison of a single- or double-injection technique for ultrasoundguided supraclavicular block: a prospective, randomized, blinded controlled study. Reg Anesth Pain Med. 2012 Jan-Feb;37(1):55-9.
12 Techasuk W, González AP, Bernucci F, Cupido T, Finlayson RJ, Tran DQ. A randomized comparison between double-injection and targeted intracluster-injection ultrasoundguided supraclavicular brachial plexus block. Anesth Analg. 2014;118(6):1363-9.

13 Casati A, Fanelli G, Beccaria P, Cappelleri G, Berti M, Aldegheri G, et al. The effects of the single or multiple injection technique on the onset time of femoral nerve blocks with $0.75 \%$ ropivacaine. Anesth Analg. 2000;91(1):1814.

14 Bigeleisen PE, Moayeri N, Groen GJ. Extraneural versus intraneural stimulation thresholds during ultrasound-guided supraclavicular block. Anesthesiology. 2009;110(6):123543.

15 Franco CD. Connective tissues associated with peripheral nerves. Reg Anesth Pain Med. 2012 Jul-Aug;37(4):363-5.

16 Morfey D, Brull R. Ultrasound-guided supraclavicular block: what is intraneural? Anesthesiology. 2010;112(1):250-2. author reply 251-2.

17 Perlas A, Lobo G, Lo N, Brull R, Chan VW, Karkhanis R. Ultrasound-guided supraclavicular block: outcome of 510 consecutive cases. Reg Anesth Pain Med. 2009 Mar-Apr;34(2): 171-6. 